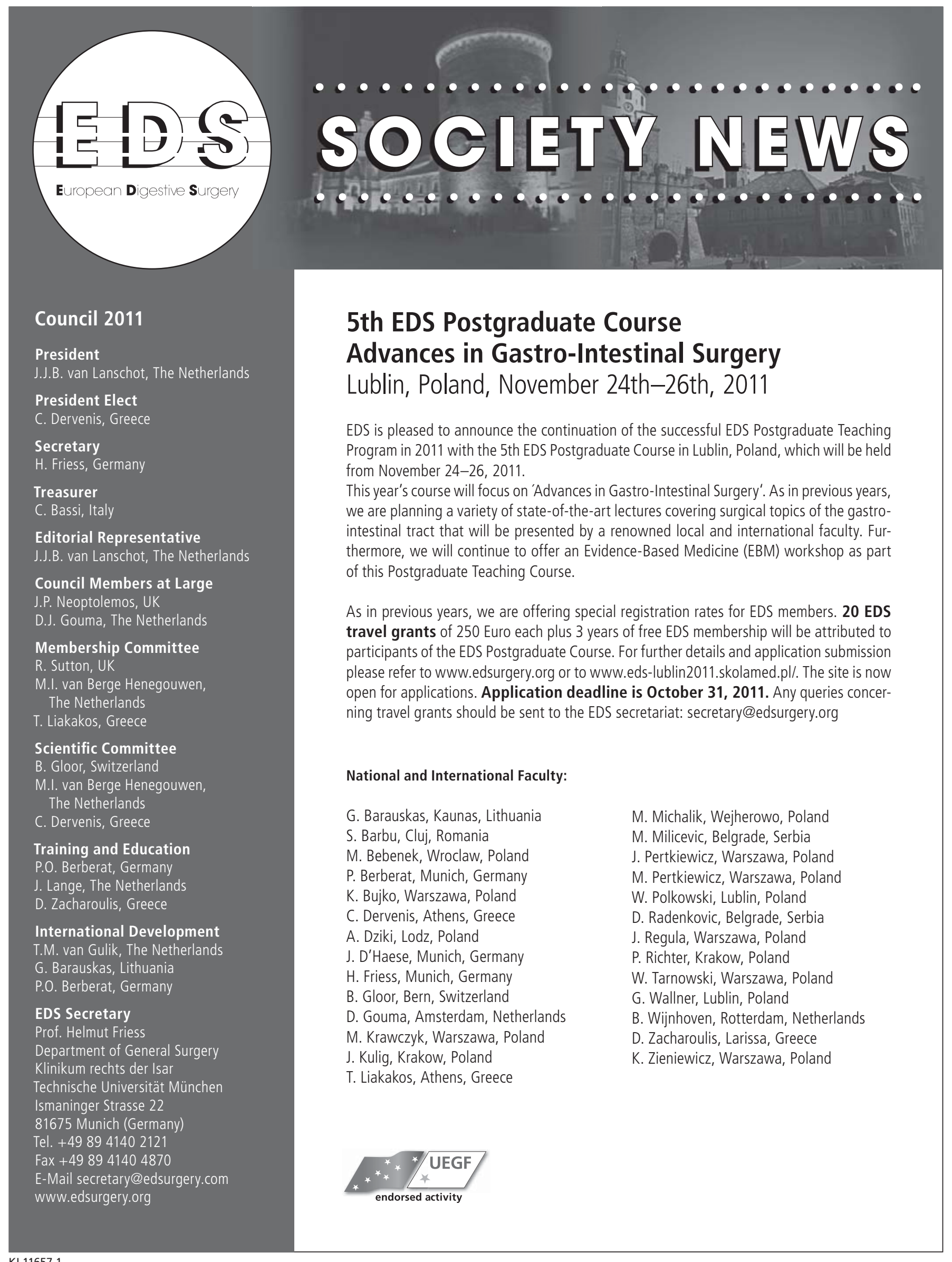




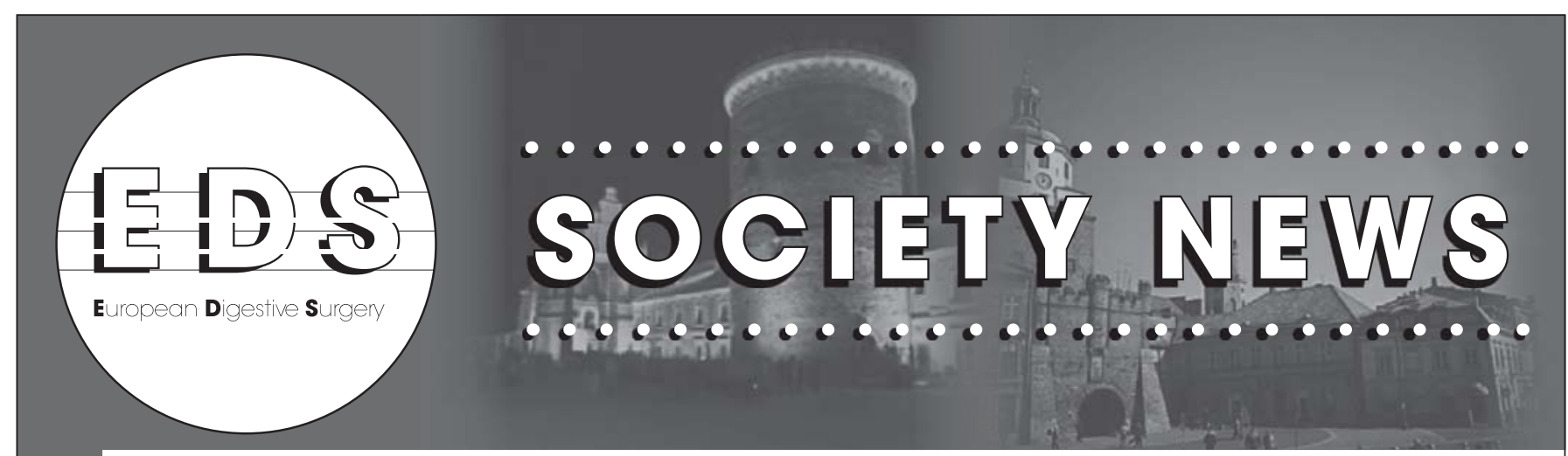

\section{Preliminary Scientific Program}

Evidence-Based Medicine Workshop

- Principles of Evidence-Based Medicine

- How to search for the best evidence?

- How to critically evaluate the evidence?

- Journal Club - practical work

- How to generate evidence? - Set up and planning of research projects/groups

- Set up and planning of clinical studies

- How to write a paper for publication?

\section{Session 1: Esophageal and Gastric Cancer}

- Surgery and minimally invasive procedures for GERD

- Transhiatal vs. transthoracic esophagectomy for cancer of the esophagus

- Extent of resection and lymphadenectomy for gastric cancer

- Neoadjuvant and adjuvant treatment in esophageal and gastric cancer

\section{Session 2: Metabolic Surgery}

- Type 2 diabetes: Indication for metabolic surgery?

- Surgery for morbid obesity

- Postoperative short bowel syndrome: parenteral nutrition and timing of surgical repair

- Pancreatic anastomosis and metabolic changes after pancreaticoduodenectomy

\section{Session 3: Video Session}

- Single-port cholecystectomy

- Surgical options in Klatskin tumors

- Transanal endoscopic microsurgery (TEM)

- Pancreatico-jejunostomy vs. pancreatico-gastrostomy

- Key steps in DPPHR for chronic pancreatitis

- Transection techniques in liver parenchyma

\section{Session 4: Hepato-Pancreato-Biliary Surgery}

- Colorectal liver metastases - extending the limits

- Liver surgery in altered parenchyma

- Surgical treatment of pancreatic cancer

- Palliative surgery for pancreatic cancer
Session 5: Colorectal Surgery I

- T1 colorectal cancer - Is local therapy enough?

- Complete mesocolic excision for colon carcinoma

- Laparoscopic and open colorectal surgery - Where are the advantages and failures?

- Metastasized colorectal cancer: Liver or primary first?

\section{Session 6: Colorectal Surgery II}

- Neoadjuvant therapy for rectal cancer - Why, when, how?

- Total mesorectal excision - how to learn and audit this technique?

- Abdomino-sacral amputation for low rectal carcinoma

- Surgical options in local recurrence of rectal cancer

\section{Session 7: Pancreatitis}

- Is there still an indication for surgery in acute pancreatitis?

- Conservative (medical/endoscopic) vs. surgical treatment of chronic pancreatitis

- Pseudocysts: When and how to treat?

- Drainage or resection procedure for chronic pancreatitis

For further information on this course please contact:

Prof. Wojciech P. Polkowski

Chairman of the Local Organizing Committee

Department of Surgical Oncology

Medical University of Lublin

Staszica 11

20-081 Lublin (Poland)

Tel. +48815344313

$\mathrm{Fax}+48815322395$

E-Mail: wojciech.polkowski@am.lublin.pl

www.eds-lublin2011.skolamed.pl

If you have any other questions please do not hesitate to contact us at the EDS secretariat:

H. Friess, MD (EDS Secretary)

J. D'Haese, MD (Assistant of Secretary)

Department of Surgery

Klinikum rechts der Isar

Technische Universität München

Ismaninger Str. 22

81675 München (Germany)

Tel.: +49 (89) 41402121

Fax: +49 (89) 41404870

E-Mail: secretary@edsurgery.org

www.edsurgery.org

www.chir.med.tum.de 